\title{
Implementation the LM35 Sensor AS Control Room Temperature using IC ATMega 8535
}

\author{
Muchdar D. Patabo \\ Electrical Engineering Dept \\ Manado State Polytechnic \\ North Sulawesi - Indonesia
}

\author{
Samsu Tuwongkesong \\ Electrical Engineering Dept \\ Manado State Polytechnic \\ North Sulawesi - Indonesia
}

\author{
Nikita Sajangbati \\ Information Technology Dept \\ Manado State Polytechnic \\ North Sulawesi - Indonesia
}

\begin{abstract}
One of the electronic technologies that have been developed in this research is to create a room temperature control prototype by implementing the LM35 sensor as a temperature controller, using the ATMega 8535 IC which is a microcontroller as a data control center, and using the $\mathrm{C}$ language with CodeVison AVR software, adjusting the display on the LCD, translating the analog signal from the LM35 sensor as temperature control and control the room so that the temperature remains stable.

The results obtained with room temperature control on the prototype can be seen on the LCD, if the controlled room temperature is greater than $25^{\circ} \mathrm{C}$, the input received from the LM35 sensor will be processed by the ATMega 8535 microcontroller then it will activate fan 1 to blow cool air that is entered in the room and fan 2 to remove hot air from inside the room. But if the temperature display on the LCD is lower than $260^{\circ} \mathrm{C}$, fan 1 and fan 2 will not be activated (Off).
\end{abstract}

\section{General Terms}

LM 35 Sensor, IC ATMega 8535

\section{Keywords}

Driver Relay, Fan, LCD

\section{INTRODUCTION}

Every day humans need fresh air to be able to live, but every day the air they breathe is reduced due to global warming, inevitably the air temperature around us changes according to the density and operation of existing factories or vehicles. Conditions of unstable or changing air temperature make it uncomfortable to be everywhere. The comfort of an airconditioned room is wanted by people who live today. However, have we ever thought that even cold is not sufficient for the needs of the human body, because there is a need for a balance between cold and hot temperatures or temperatures ranging from $25^{\circ} \mathrm{C}-28^{\circ} \mathrm{C}$, which is the normal temperature needed to make our bodies always feel good.

If the room temperature is controlled greater than $25 \mathrm{oC}$, then the input received from the temperature sensor will be processed by the microcontroller then it will activate Fan 1 to blow cold air to the room and Fans2 to remove hot air from the room. So that the controlled room still feels comfortable.

This research includes planning and making a prototype of an indoor temperature control system that is developed to support technological developments in terms of control systems so that it will provide benefits to its users.

\section{LITERATURE REVIEW}

\subsection{Control System}

Each control system has at least one controller and an actuator which is also referred to as the final control element. As shown in Figure 1., the controller is the intelligence of the system and is usually electronic. The input to the controller is called a reference (setpoint), a signal that represents the desired output system. An actuator is an electromechanical device that receives a signal from the controller and becomes a kind of physical activity. The last block in Figure 1 is a process and has an output that is a controlled variable. The process block represents the physical process by the actuator and the controlled variables with measurable results of the process.

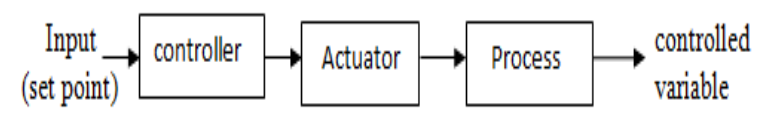

Figure 1. Control system block diagram

There are two general configurations of control systems, namely, open-loop systems and feedback control systems or often called closed-loop systems.

\subsection{LM35 Temperature Sensor}

The temperature sensor in this study uses the LM35 sensor, where the output of the LM35 sensor can provide 8-bit data output which states the changing conditions of the ambient temperature. When there is a change in temperature, there will be a change in the resulting output data, where the change is in the form of a difference in voltage generated.

LM35 is a temperature detection tool has the following characteristics:

1. Working at a voltage rating of $4 \mathrm{~V}$ to $30 \mathrm{~V}$.

2. The temperature reading ranges from $-55{ }^{\circ} \mathrm{C}$ to $150^{\circ} \mathrm{C}$.

3. With an increase in temperature of $1{ }^{\circ} \mathrm{C}$, the output voltage will increase by $10 \mathrm{mV}$.

4. Has a drain current of less than $60 \mu \mathrm{A}$.

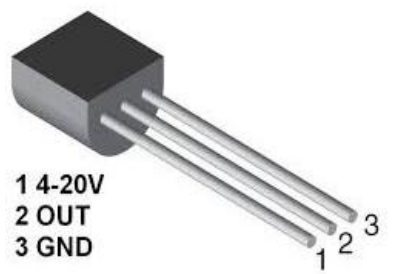

Figure 2. The Physical Form of Sensor LM35 


\subsection{Microcontroller ATMega 8535}

ATMega 8535 is an 8-bit microcontroller made by Atmel for the AVR family, ATMega8535 uses RISC (Reduced Instruction Set Computing) architecture. AVR or an abbreviation of Alf and Vegard's Risc Processor is a microcontroller chip produced by Atmel.

The ATMega8535 microcontroller has a total of 40 pins, of which 32 pins are used for I / O ports which can be input/output pins according to configuration. The 32 pins are divided into 4 parts (ports), each of which consists of 8 pins. The other pins are used for the oscillator circuit, supply voltage, reset, and reference voltage for the ADC. For more details, the ATMega8535 pin configuration can be seen in Figure 3 .

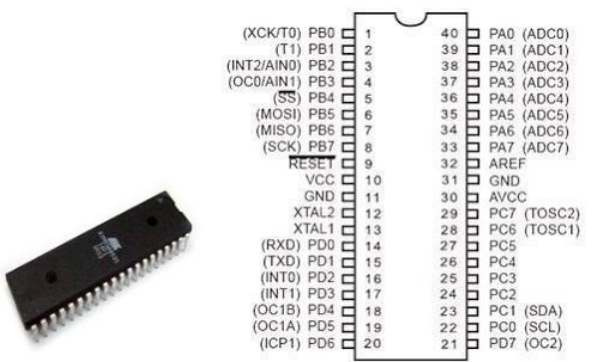

Figure 3. ATMega 8535 Pin Configuration

\subsection{LCD (Liquid Crystal Display)}

LCD is a screen part of the display module that displays the desired character. The LCD screen uses two polarizing material sheets and a liquid crystal between the two sheets. The electric current that passes through the liquid causes the crystals to flatten so that light cannot pass through each crystal, hence such a light arrangement determines whether light can pass through or not. So that it can change the shape of the liquid crystals to form a display of numbers or letters on the screen. In this instrument, the size type of LCD used is a 2 $\mathrm{x} 16 \mathrm{LCD}$ as shown below.

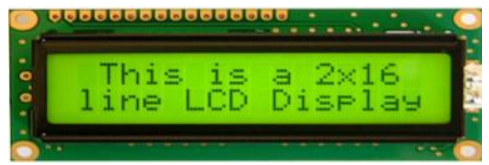

Figure 3. LCD Physical Form

\section{METHODOLOGY}

System design in this study uses a design method that begins with designing a control system block diagram, system flow chart, designing a power supply circuit, relay drivers for on/off Fan, and LCD.

Designing a temperature sensor to detect room temperature, making the ATMega 8535 microcontroller program as a system control center that functions to receive data from sensors and process the data then activate Fan1 and Fan2 according to the specified temperature settings as well as making room temperature control prototypes then conducting system testing and device evaluation hardware or software.

\section{RESULT AND DISCUSSION \\ 4.1 Control System Block Diagram}

The design of the control system block diagram aims to describe and determine the components that support the work of the room temperature control system.

The control system block diagram is shown in Figure 4. with a job description as follows:

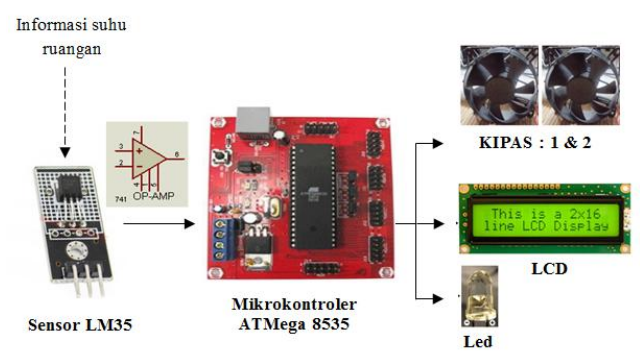

Figure 4. Control System Block Diagram

From the block diagram of the system can be explained the order of the system, namely:

1. The LM35 sensor captures room temperature information and sends it to the microcontroller.

2. If the measured temperature is above the normal level (greater than $25^{\circ} \mathrm{C}$ ), the microcontroller will process the data so that fan 1 and fan 2 will be turned $\mathrm{ON}$ to blow air into the room.

If the measured temperature is less than $26^{\circ} \mathrm{C}$ then Fan 1 and Fan2 will be OFF.

Besides, the microcontroller also activates the LCD to monitor the measured temperature in the room.

\subsection{Power Supply Circuit Design}

The power supply circuit serves to provide electrical power to the room temperature system.

To run all the hardware of this system, electrical power is needed following the needs of each device. In the controller circuit, a voltage of 5 volts DC is required with a maximum current of $1 \mathrm{~A}$. Likewise for supporting circuits such as relay drivers requiring a voltage of 12 volts DC, LCD requires a voltage of 5 volts DC and other supporting circuits.

For this reason, it is necessary to make a power supply circuit that can supply the above needs, with a voltage source from 220 Volt by PLN in the form of AC, a transformer with a current limit of $3 \mathrm{~A}$ is used to convert the voltage value to 12 volts and rectify it through a rectifier circuit then turn it into a voltage constant (regulated) by using a regulator 7812 for a voltage of 12 volts and 7805 for a voltage of 5 volts. The power supply circuit can be seen in Figure 5.

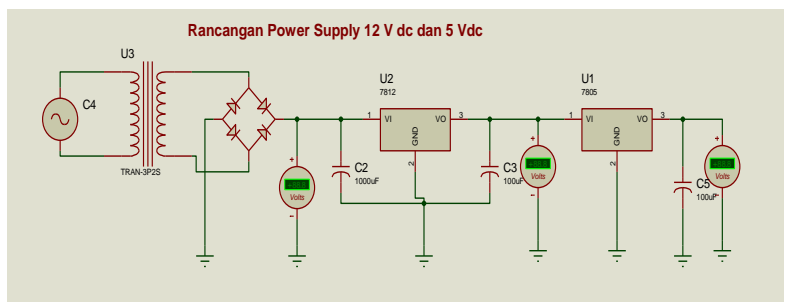

Figure 5. Power Supply Circuit Design

\subsection{Temperature Sensor Driver Design}

The LM35 IC has high reliability with high input impedance and low output impedance. Has a sensitivity of $\pm 10 \mathrm{mV} /{ }^{\circ} \mathrm{C}$ and an operating temperature range of $-55^{\circ} \mathrm{C}$ to $150^{\circ} \mathrm{C}$.

The supply voltage used is $5 \mathrm{~V}$ DC. The output voltage from the sensor is $10 \mathrm{mV} /{ }^{\circ} \mathrm{C}$. The planned temperature setting range is $26^{\circ} \mathrm{C}-30^{\circ} \mathrm{C}$, according to the temperature of the room, so the sensor output is $260 \mathrm{mV}-300 \mathrm{mV}$. The output from the temperature sensor is then connected to the ATMega 8535 microcontroller which functions as an ADC input. 
Figure 6. shows the temperature sensor driver circuit.

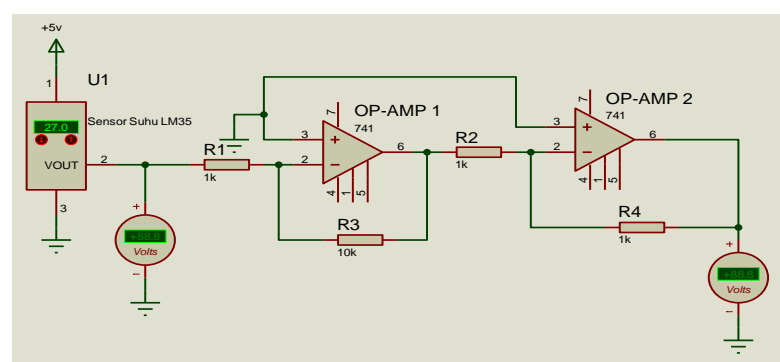

Figure 6. Driver Temperature Sensor

\subsection{LCD Design}

LCD (Liquid Crystal Display) is an electronic device that functions to display the output of a system by forming an image or image on a screen.

In this design using an ATMega8535 microcontroller with Port $\mathrm{C}$ as the output. The components used in this LCD circuit consist of ATMega8535 microcontroller, 16x2 LCD, potentiometer, 5-volt power supply, and ground. The following is a design of the LCD circuit with the ISIS Proetues program.

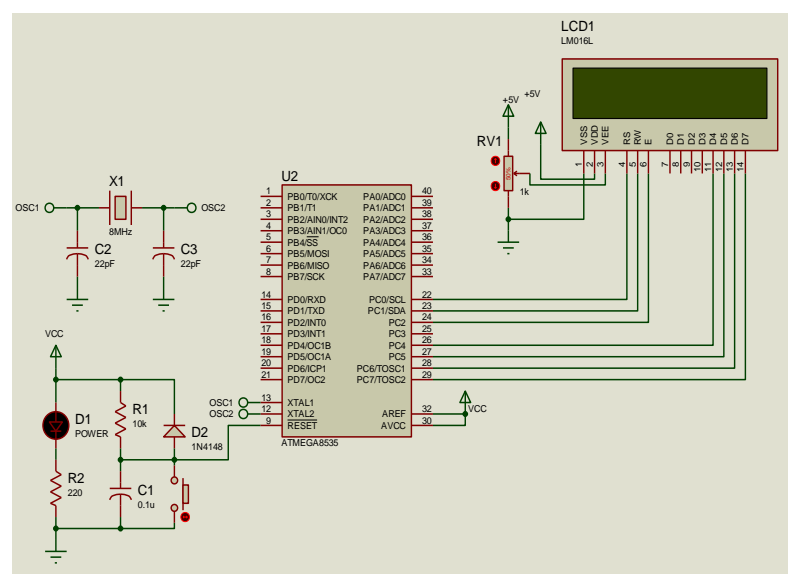

Figure 7. LCD Circuit Design

\subsection{Fan Driver Design}

This fan driver uses a transistor that functions as a switch. The function of this circuit is to activate and deactivate the work of the fan. The fan diver design can be seen in Figure 8 .

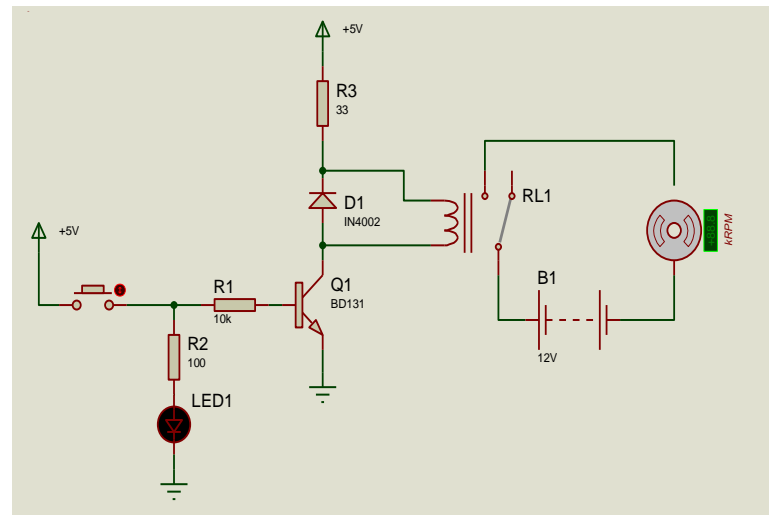

Figure 8. Fan Driver Circuit Design

In figure 8 , under normal circumstances, the push button has not been pressed, so LED1 and the fan are not active because there is no current passing through the base of the transistor.

When the push button is pressed, the current will pass through resistance $\mathrm{R} 1$ and $\mathrm{R} 2$, because the resistance $\mathrm{R} 2$ is attached to the LED and connected to neutral, the LED as an indicator will light up. And the current passing through R1 will enter through the base of the transistor so that the collector and emitter are connected. The transistor functions as a switch so that the relay works and the DC can be connected to the 12 VDC fan load.

\subsection{Temperature Sensor Design with Microcontroller}

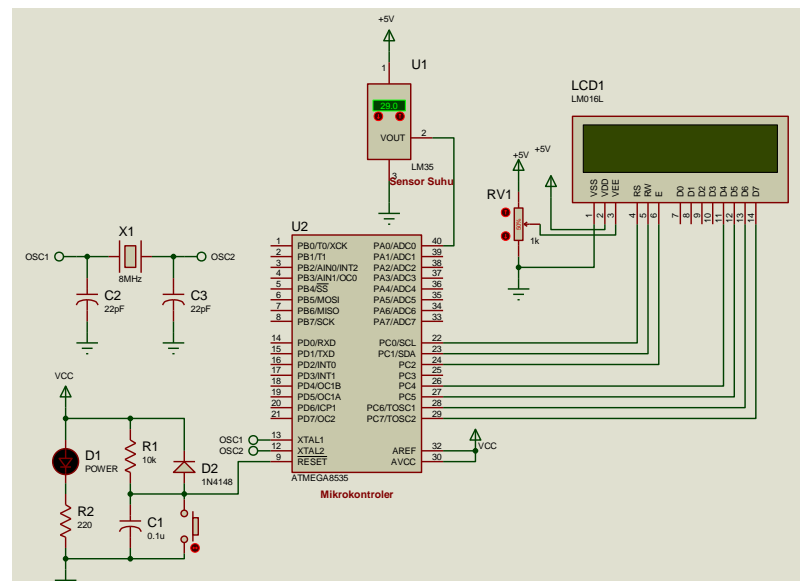

Figure 7. Temperature Sensor Design with Microcontroller

The circuit above is a series of using ATMega8535 which is connected to a temperature sensor. The LM35 temperature sensor is connected to a voltage source and the output of the sensor is inserted into the Analog pin of ATMega. then this data is converted by ATMega and then displayed the temperature measured by the sensor on the LCD screen.

\subsection{Room Temperature Control System Design}

The design of a room temperature control system with an ATMega 8535 microcontroller aims to facilitate the manufacture of hardware, where the integrated control system circuit is shown in Figure 8.

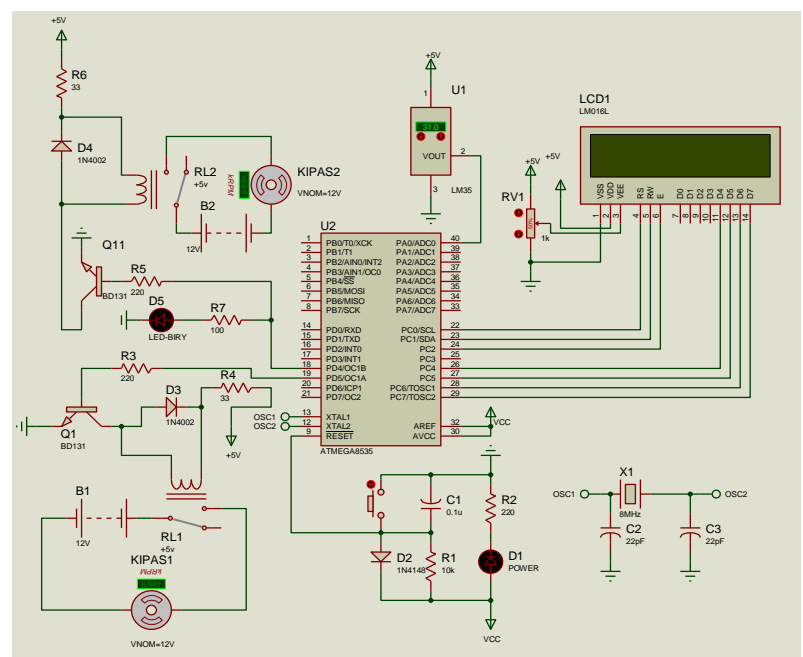

Figure 8. Room Temperature Control System Design

The design of this room temperature control system is an integrated circuit of 5 and 12 Volt DC power supplies, LM35 Temperature Sensor, ATMega8535 Minimum Microcontroller system, LCD, Fan1 to blow cold air into the room, and fans to remove indoor air and LED indicators that will be turned on if 
the room temperature exceeds the set temperature.

\subsection{Design software}

The software that is embedded in the ATMega 8535 microcontroller functions to operate the microcontroller equipment to match what is expected. The software used is Codevision AVR V2.03.4 which is based on the C language. In designing the software, it uses an algorithm in the form of a flowchart, the making of this algorithm aims to simplify programming. Figure 9. shows the flowchart of the room temperature control system

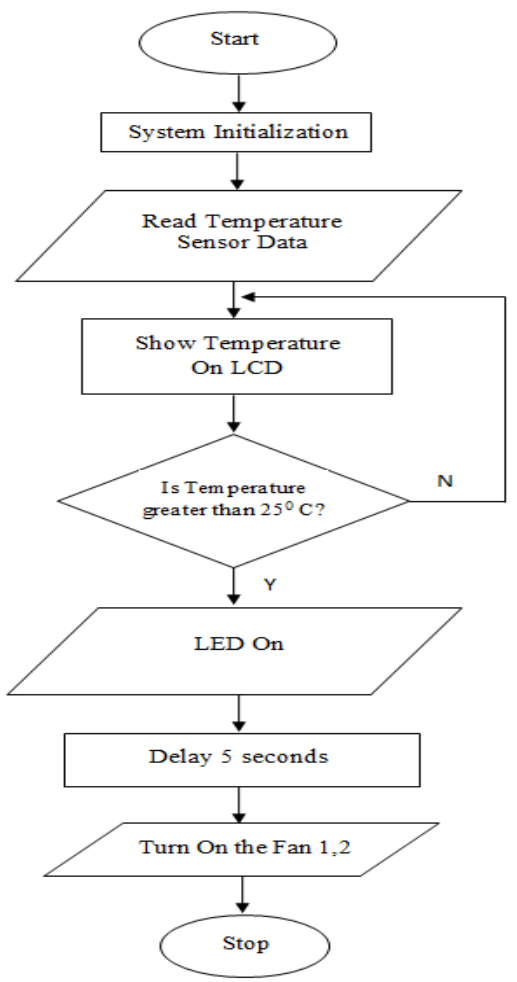

Figure 9. Flow Chart of Room Temperature Control System

Flow chart description:

1. When the system is activated, the system initializes the microcontroller used, calls the library (prepares commands that can be used when using the ATMega 8535 microcontroller).

2. Read data from the temperature sensor.

3. Displays the temperature sensor data on the LCD.

4. If the detected temperature in the room is greater than $25^{\circ} \mathrm{C}$, the microcontroller will process the data so that the fan 1 will be turned ON to suck cold air into the room and the fans will be active to remove hot air in the room with the LED ON indicator.

5. If the room temperature is less than $26^{\circ} \mathrm{C}$ then fan 1 , fan2 and LEDs will be turned OFF.

\section{TESTING SYSTEM}

\subsection{Temperature Sensor Circuit Testing}

Testing of the temperature sensor circuit is carried out on each change in the output voltage of the LM 35 temperature sensor, where the change in voltage depends on the temperature detected by the sensor. Testing the temperature sensor circuit is shown in Figure 10.

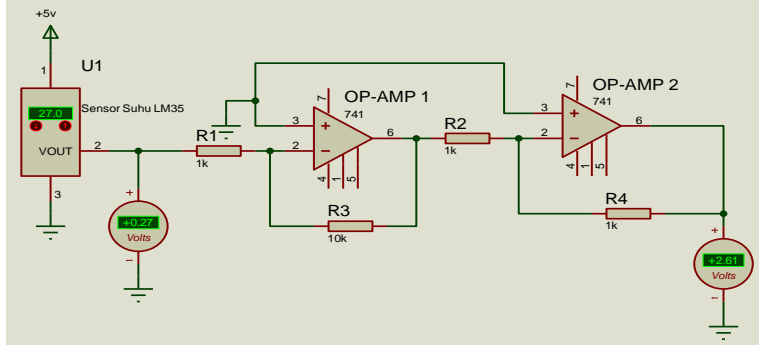

Figure 10. Testing the Temperature Sensor Circuit

From the results of the tests carried out, it is obtained data that for each increase of $15^{\circ} \mathrm{C}$, the measured output voltage through V1 is $0.15 \mathrm{~V}$. After passing through the amplifier circuit, where the gain is 10 times, then the voltage measured through $\mathrm{V} 2$ is $1.5 \mathrm{~V}$.

The test results of the temperature sensor circuit are shown in Table 1.

Table 1. Testing The Temperature Sensor Circuit

\begin{tabular}{lll}
\hline $\begin{array}{l}\text { Temp. } \\
\text { LM 35 } \\
\left({ }^{0} \mathrm{C}\right)\end{array}$ & $\begin{array}{l}\text { Output V1 } \\
\text { (Volt) }\end{array}$ & $\begin{array}{l}\text { Output } \mathrm{V} 2 \\
\text { (Volt) }\end{array}$ \\
\hline 15 & 0.15 & 1.5 \\
18 & 0.18 & 1.8 \\
20 & 0.2 & 2 \\
24 & 0.24 & 2.4 \\
25 & 0.25 & 2.5 \\
27 & 0.27 & 2.7 \\
29 & 0.29 & 2.9 \\
30 & 0.30 & 3.0 \\
\hline
\end{tabular}

\subsection{Testing ADC (Analog to Digital Converter)}

The ADC test is carried out on any changes in the voltage generated by the output of the potentiometer circuit. The function of the ADC is to convert analog signal input to a digital signal. Figure 11. shows the ADC Test.

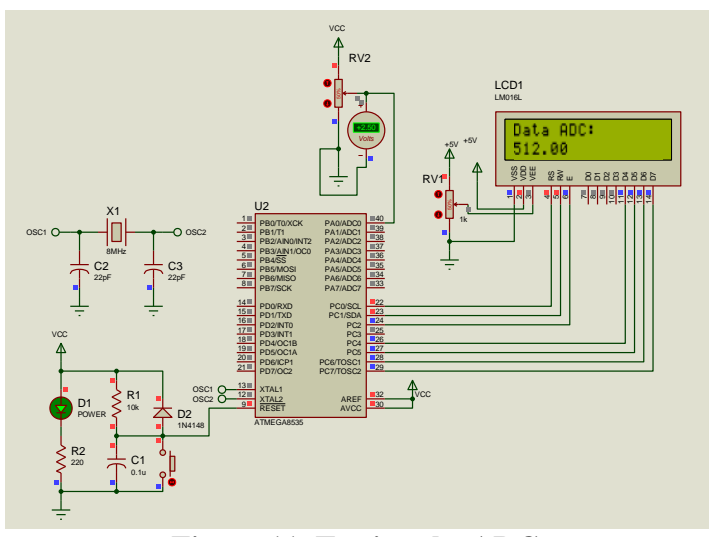

Figure 11. Testing the ADC

The ADC test result data will later be used as reference data in programming. Table 2 shows the ADC test result data for each change in the input voltage which is the output of the potentiometer circuit. 
Table 2. ADC Testing

\begin{tabular}{llll}
\hline $\begin{array}{l}\text { Input ADC } \\
(\mathrm{V})\end{array}$ & $\begin{array}{l}\text { Output ADC } \\
\text { (Data) }\end{array}$ & $\begin{array}{l}\text { Calculation } \\
\text { (Data) }\end{array}$ & $\begin{array}{l}\text { Error } \\
\%\end{array}$ \\
\hline 2,48 & 518,27 & 518,26 & 0,002 \\
2,62 & 547,43 & 547,53 & 0,018 \\
2,813 & 586,1 & 586,81 & 0,192 \\
2,82 & 588,02 & 589,32 & 0,220 \\
\hline
\end{tabular}

Theoretically, to test the amount of ADC data, namely by calculating it according to the equation:

$$
\begin{aligned}
& \quad \text { Data } A D C=\frac{\text { Vin } \times 1024}{\text { Vref }} \\
& \text { Where : } \\
& \text { Vin }=\text { ADC input voltage } \\
& \text { Vref }=\text { ADC reference voltage }(4.9 \text { Volts })
\end{aligned}
$$

a. For the first test when the ADC input is 2.48 volts, the data obtained is 518.27 . Whereas theoretically, the calculation data is as follows:

$$
\begin{aligned}
\text { Data } A D C & =\frac{\text { Vin } \times 1024}{\text { Vref }} \\
& =\frac{2,48 \times 1024}{4,9} \\
& =518,26
\end{aligned}
$$

The amount of error data from the test and calculation results is:

$$
\begin{aligned}
\operatorname{Error}(\%) & =\frac{\text { calculation data-measurement data }}{\text { calculation data }} \times 100 \% \\
& =\frac{518,26-518,27}{518,26} \times 100 \% \\
& =-0,002 \%
\end{aligned}
$$

in the same way:

b. For the second test,

$$
\begin{aligned}
\operatorname{Error}(\%) & =\frac{547,53-547,43}{547,53} \times 100 \% \\
& =0,018 \%
\end{aligned}
$$

c. For the third test,

$$
\begin{aligned}
\operatorname{Error}(\%) & =\frac{587,23-586,1}{587,23} \times 100 \% \\
& =0,192 \%
\end{aligned}
$$

d. For the fourth test,

$$
\begin{aligned}
\operatorname{Error}(\%) & =\frac{589,32-586,81}{591,4} \times 100 \% \\
& =0,220 \%
\end{aligned}
$$

\subsection{LCD Testing}

LCD testing was carried out by simulating the display of running text using ISIS Proteus 7.8 software. as a hardware representation.

Testing using the ATMega 8535 microcontroller as a microprocessor to run the program displaying the characters on the LCD with Port C as the output.

The program was created using a $\mathrm{C}$ language program with Code Vision AVR V2.03.4 software which has a code wizard used in the initialization of the microcontroller to be used.

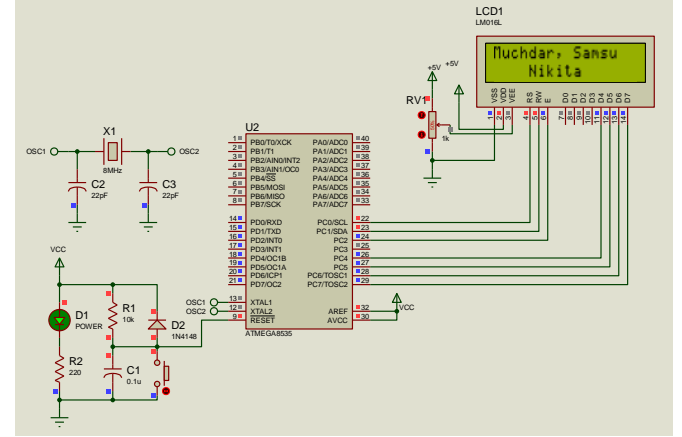

Figure 12. Testing the LCD Circuit

\subsection{Testing Driver Relay On/Off FAN}

Testing the relay driver for on/off Fan is carried out to test the magnitude of the input voltage, base current, and relay voltage when the circuit is active.

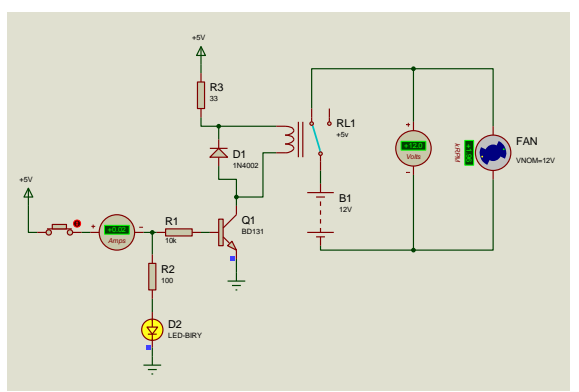

Figure 13. shows a test of the relay driver circuit for on/off Fan.

Figure 13. Testing Relay Driver Circuit for On/Off Fun

When the push button is pressed, the current will pass through resistance $\mathrm{R} 1$ and $\mathrm{R} 2$, because the resistance $\mathrm{R} 2$ is attached to the LED and connected to neutral, the LED as an indicator will be turned on. And the current passing through R1 will enter through the base of the transistor so that the collector and emitter are connected. The transistor functions as a switch so that the relay works and the DC can be connected to the 12 VDC fan load and the rotating fan.

The results of the relay driver circuit testing are shown in Table 3.

Table 3.Test data driver relay On/Off Fun

\begin{tabular}{ccc}
\hline $\begin{array}{c}\text { Tegangan Input } \\
(\mathrm{V})\end{array}$ & $\begin{array}{c}\text { Arus Basis } \\
(\mathrm{mA})\end{array}$ & $\begin{array}{c}\text { Tegangan Relay } \\
(\mathrm{V})\end{array}$ \\
\hline 5 & 2,0 & 12,0 \\
\hline
\end{tabular}

The results obtained in Table 3 shows that the input voltage that goes to the base terminal Q1 is 5 volts. The amount of current obtained is $2.0 \mathrm{~mA}$. When the base of Q1 receives a current of $2.0 \mathrm{~mA}$, the circuit will be activated so that a voltage of 12.0 volts is obtained at the A1 and A2 legs of the relay.

Theoretically, the amount of current flowing to the base terminal of TR 1 is as follows:

$$
I_{B}=\frac{V i n-V B E}{R B}
$$

Where:

$\mathrm{IB}=$ Base current 
Vin $=$ Input voltage $(5$ Volt $)$

$\mathrm{VBE}=$ Base-emitter voltage $(0.6$ Volt

for transistor silicon)

$\mathrm{RB}=$ Base resistance $(1 \mathrm{~K} \Omega)$

Then:

$$
\begin{aligned}
V_{B E} & =V_{B E} \mathrm{TR} 1+V_{B E} \mathrm{TR} 2 \\
& =0,6+0,6 \\
& =1,2 \text { Volt. } \\
I_{B} & =\frac{5-1,8}{1000} \\
& =0,0038 \text { Ampere. }
\end{aligned}
$$

\subsection{Room Temperature Control System Testing}

Testing the room temperature control system was carried out by simulating the display using the ISIS Proteus 7.8 software. as a hardware representation.

The output of the LM35 temperature sensor becomes the input of the microcontroller, while the output of the microcontroller is a $16 \times 2 \mathrm{LCD}$ and a fan.

The temperature sensor reads analog data in real-time in the form of room temperature data then the data is submitted into the microcontroller, the data is converted into digital data by the microcontroller to be processed and the output is an active fan to cool the room and real-time temperature data display on the LCD. For a comfortable room temperature, it is set between a temperature range of $25^{\circ} \mathrm{C}$ to $28^{\circ} \mathrm{C}$. if the room temperature read by the sensor exceeds $25^{\circ} \mathrm{C}$ then the fan will be automatically turned on and cool down the room to a temperature of $25^{\circ} \mathrm{C}$ and if the temperature is below $25^{\circ} \mathrm{C}$ the fan will be automatically turned off. This is done to save the electrical energy used in the room.

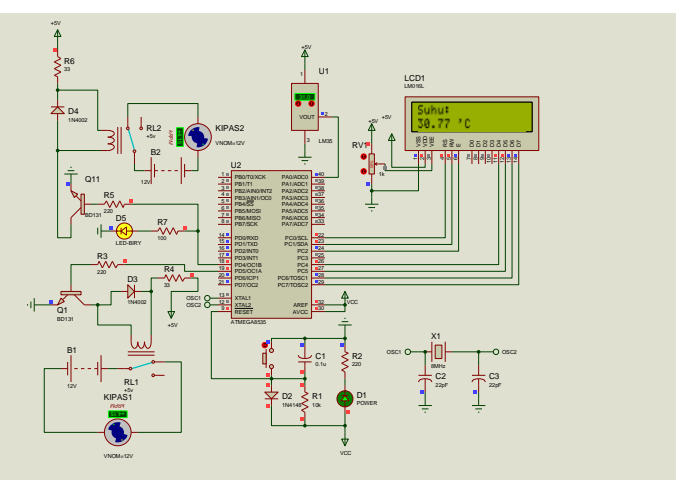

Figure 14. Testing of Room Temperature Control Systems Greater Than 300 C

Figure 14 shows that when the system is active, the temperature sensor as input from the microcontroller will be processed by the microcontroller and will be displayed on the room temperature $\mathrm{LCD}$ at that time, if the room temperature is greater than $30^{\circ} \mathrm{C}$, the microcontroller will activate the fan 1 which is regulated by PIND. 4 on the PORTD of the microcontroller, if PIND. 4 has a voltage of 5 volts or logic 1 it will turn the transistor $\mathrm{ON}$. The transistor functions as a switch so that the relay works and the DC can be connected to the 12 VDC fan load and the rotating fan. Then fan 1 works to blow cold air into the room.

The fan drive is regulated by PIND.5 on the PORTD of the microcontroller, so if PIND. 5 has a voltage of 5 volts or logic 1 it will turn the transistor ON. When the transistor is ON the transistor functions as a switch so that the relay works and the DC can be connected to the 12 VDC fan load and the fan rotates. Fans work to remove hot air from the room out. And if the room temperature is less than $260 \mathrm{C}$, the transistor will be turned OFF and the relay does not work so that fan 1 and fan2 do not rotate (OFF) as shown in Figure 15.

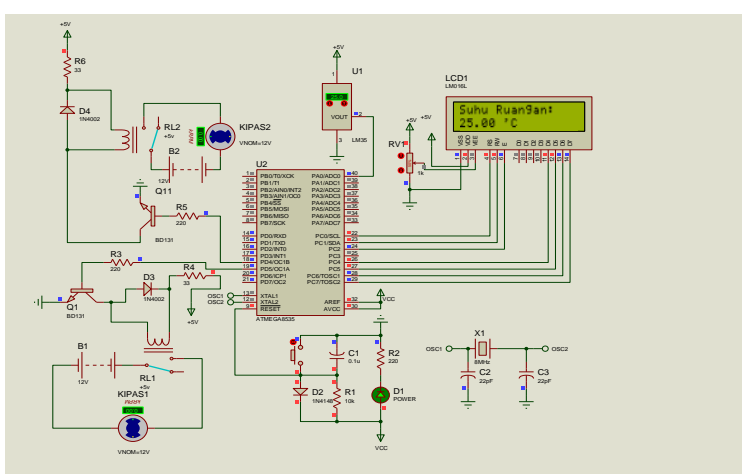

Figure 15. Testing Room Temperature Control System Less than $26^{\circ} \mathrm{C}$

\subsection{Testing Room Temperature Control Systems on Prototype}

Testing the room temperature control system on the prototype is carried out by connecting the power supply system with a voltage source from PLN 220 Volt. As shown in Figure 16

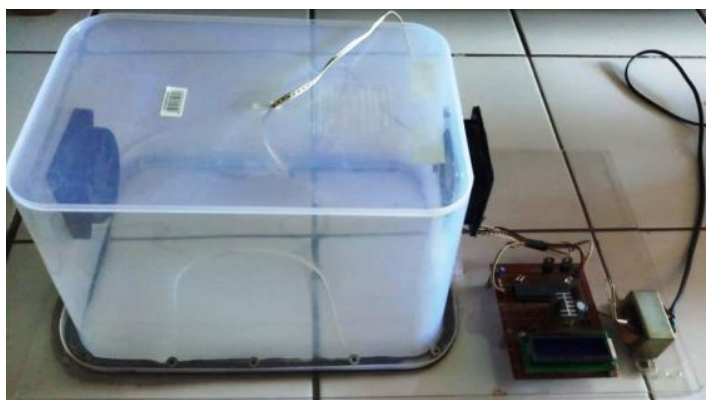

Figure 16. The prototype of the Room Temperature Conditioning System

5.6.1. Temperature Sensor Testing Compared with Temperature Measurement

Testing the room temperature sensor displayed on the LCD is compared with a temperature measuring instrument aiming to calibrate the program results displayed on the LCD with a thermometer. The results on the LCD show that the measured room temperature is $28.27^{\circ} \mathrm{C}$ and the measurement results on the measuring instrument are $28^{\circ} \mathrm{C}$. As shown in Figure 17 .

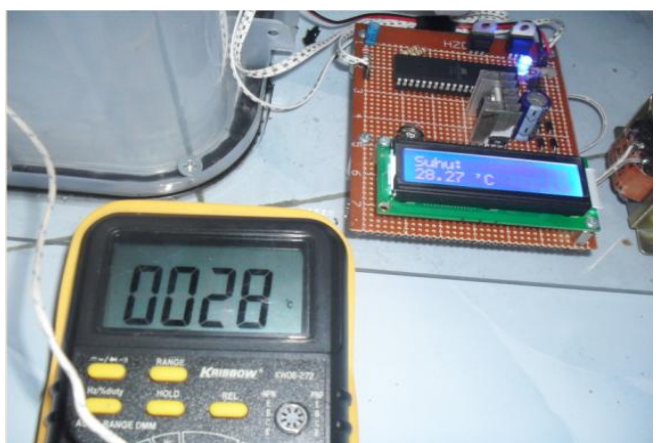

Figure 17. Display of Room Temperature compared with a Temperature Measurement Tool 


\subsubsection{Room Temperature Control System Testing} After the circuit is simulated and validated, the next step is designing the hardware circuit and testing the system. The results of designing a temperature control system hardware circuit are as follows:

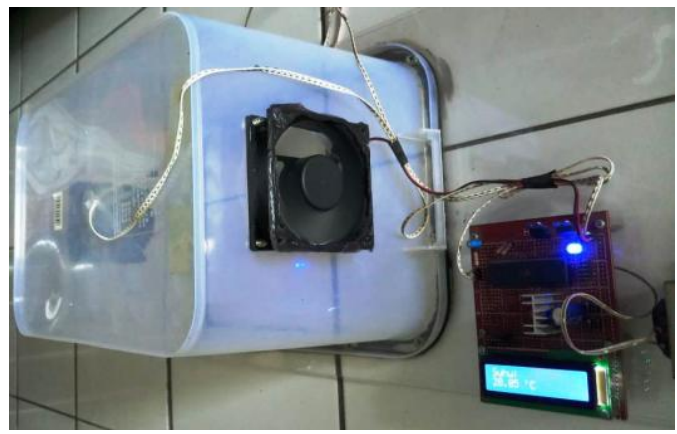

Figure 18. Testing Room Temperature Control System

The temperature control system functions to get room temperature data automatically through the LM35 temperature sensor then it is displayed on the LCD and to control the room temperature automatically by turning the fan on and off. If the room temperature exceeds the threshold, the fan will be turned on until the temperature reaches the lower threshold, after the temperature exceeds the lower threshold, the fan will be automatically turned off. The test was carried out by comparing the temperature of the thermometer with the temperature sensor readings, testing the temperature sensor three times at a temperature of $25^{\circ} \mathrm{C}$ to $35^{\circ} \mathrm{C}$, the results obtained were then averaged. The results of the average temperature sensor are then compared with the measured temperature, the difference is sought. This difference shows the error value that occurs in the measurement. The error value can be calculated using a formula :

\section{The difference in Sensor Measurement Measurement temperature \\ x $100 \%$}

The results of temperature sensor measurements can be seen in table 4:

Table 4.1. Room Temperature Measurement Results

\begin{tabular}{|c|c|c|c|c|c|c|}
\hline \multirow{2}{*}{$\begin{array}{c}\text { Measure } \\
\text { ment } \\
\text { temperat } \\
\text { ure }\left({ }^{0} \mathrm{C}\right)\end{array}$} & \multicolumn{3}{|c|}{ Temperature Sensor $\left({ }^{0} \mathrm{C}\right)$} & \multirow[b]{2}{*}{$\begin{array}{l}\text { Testing } \\
\text { Average }\end{array}$} & \multirow[b]{2}{*}{$\begin{array}{c}\text { Differ } \\
\text { ence }\end{array}$} & \multirow[b]{2}{*}{ Error } \\
\hline & Test 1 & Test 2 & Test 3 & & & \\
\hline 25 & 25.21 & 25.62 & 25.42 & 25.28 & 0.28 & 1.13 \\
\hline 26 & 26.62 & 26.38 & 26.44 & 26.48 & 0.48 & 1.85 \\
\hline 27 & 27.00 & 27.24 & 27.08 & 27.11 & 0.11 & 0.40 \\
\hline 28 & 28.42 & 28.06 & 28.06 & 28.18 & 0.18 & 0.64 \\
\hline 29 & 29.64 & 29.55 & 29.84 & 29.68 & 0.68 & 2.33 \\
\hline 30 & 30.63 & 30.62 & 30.45 & 30.70 & 0.70 & 1.89 \\
\hline 31 & 31.83 & 31.83 & 31.65 & 31.77 & 0.77 & 2.48 \\
\hline 32 & 32.75 & 32.71 & 32.73 & 32.72 & 0.72 & 2.26 \\
\hline 33 & 33.06 & 33.48 & 33.67 & 33.74 & 0.74 & 2.23 \\
\hline 34 & 34.52 & 34.54 & 34.58 & 34.55 & 0.55 & 1.61 \\
\hline 35 & 35.49 & 35.63 & 35.65 & 35.62 & 0.62 & 1.78 \\
\hline \multicolumn{5}{|c|}{ Average } & 0.58 & 1.86 \\
\hline
\end{tabular}

The test results are shown in table 4 . above show that the measurement results are quite good. The temperature measurement obtained shows an average error of $1.86 \%$. This difference in measurement occurs because the rounding process of the results on the sensor and the calibration process is still not good. The measurement results are then graphed as follows:

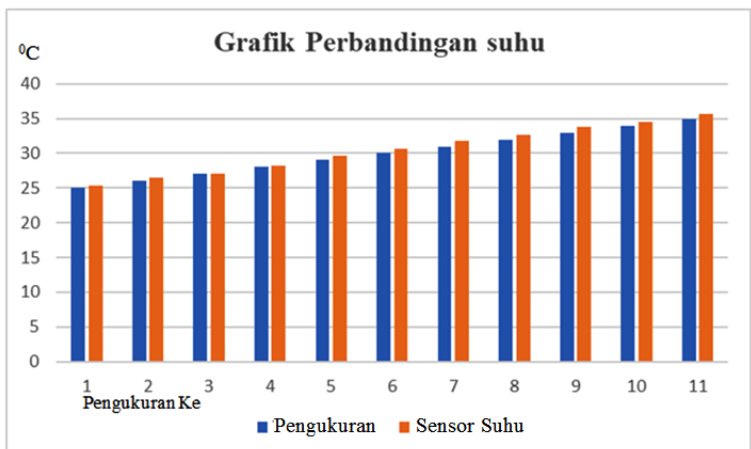

Figure 19. Temperature Comparison Graph

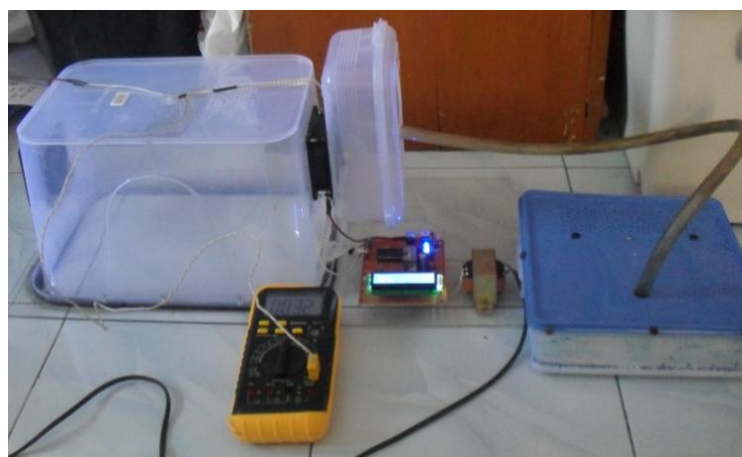

Figure 20. Overall Room Control System Prototype

When the system is activated, the LCD shows the current room temperature, if the room temperature is $25 \mathrm{oC}$, the microcontroller will activate the fan 1 set by PIND.4 on the PORTD of the microcontroller, so if PIND. 4 has a voltage of 5 volts or logic 1 it will make the transistor ON. So that fan 1 works to blow cold air into the room.

The fan drive is regulated by PIND.5 on the PORTD of the microcontroller, so if PIND.5 has a voltage of 5 volts or logic 1 it will turn the transistor ON. So that the fans work to remove hot air from the room out. And if the room temperature is less than $26 \circ \mathrm{C}$, fan 1 and fan 2 would not work (OFF).

\section{CONCLUSION}

From the results of the tests carried out, it can be concluded as follows:

1. From the measurement and calculation, there is a difference in $\mathrm{ADC}$ output data with an average error difference of $0.108 \%$.

2. The test results of the relay driver circuit use Transistor BD131 as a switch so that the relay will work if the Base Q1 input voltage is 5 volts with a current of $2.0 \mathrm{~mA}$.

3. The test results of the temperature sensor with a thermometer showed an average error of $1.86 \%$ so that the LM35 temperature sensor could be used to control room temperature.

4. For a comfortable room temperature, it is set between $25^{\circ} \mathrm{C}$ to $28^{\circ} \mathrm{C}$. if the room temperature read by the sensor is greater than $25^{\circ} \mathrm{C}$ then the fan will be automatically turned on and cool down the room to $26^{\circ} \mathrm{C}$ and if the temperature is below $26^{\circ} \mathrm{C}$ then the fan will be automatically turned off. 


\section{THANK-YOU NOTE}

The authors would like to thank P3M Politeknik Negeri Manado and all those who can not be mentioned one by one so that this research can be done.

\section{REFERENCES}

[1] Abdul Kadir, 2013, A Practical Guide to Studying Microcontroller Applications and Its Programming Using Arduino, Andi Yogyakarta.

[2] Singgih Adhi Nugroho, 2013, Room Temperature Detector with AT89S51 Microcontroller-Based Manual Control Button, Seruni - National Seminar on Informatics and Computer Science FTI UNSA.

[3] Aryandhi, Mozart Wilson, 2013, Application of Fuzzy Inference for Automatic Room Temperature Control in Air Conditioners (AC), Proceedings of FMIPA, Pattimura University 2013 - ISBN: 978-602-97522-0-5,
Yudha Dwi Talakua FMIPA Pattimura University, Ambon.

[4] Erwin Fadhila, Hendi H. Rachmat, 2014, Microcontroller Based Temperature Control in Egg Incubators, Reka Elkomika Journal 2337-439X October 2014, Electrical Engineering, Bandung National Institute of Technology.

[5] Dias Prihatmoko, 2016, Design and implementation of room temperature controllers based on Arduino Uno microcontrollers, Jurnal Simetris Vol 7 No. 1 April 2016 ISSN: 2252-4983, Faculty of science and technology, Islamic University Nahdlatul Ulama Jepara.

[6] Syahwil, M., 2013, Easy Guide to Simulation and Practice of Arduino Microcontroller. Yogyakarta: Publisher ANDI. 